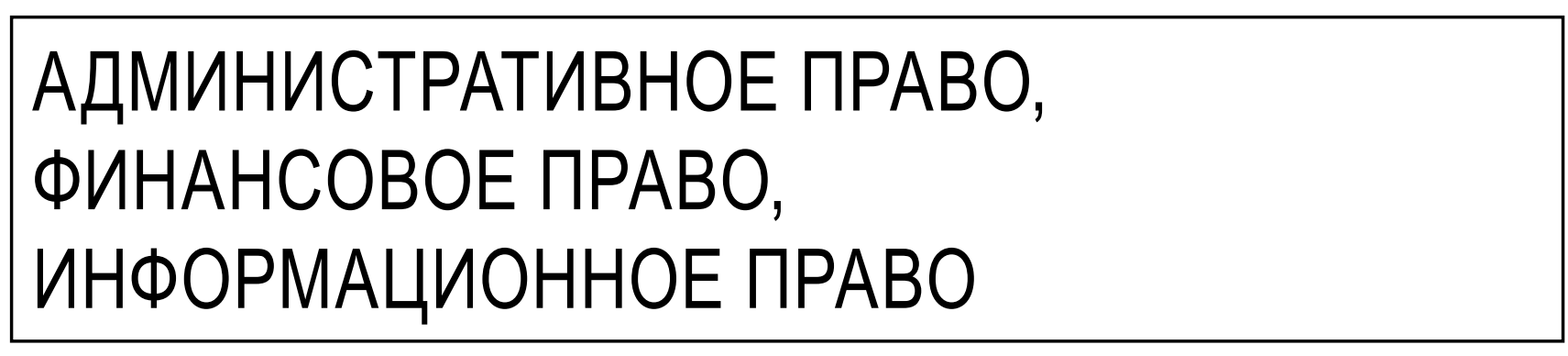

К.А. Пономарева

\title{
ПЕРСПЕКТИВЫ БАНКРОТСТВА МУНИЦИПАЛЬНЫХ ОБРАЗОВАНИЙ: ПРЕВЕНТИВНЫЕ И ОЗДОРОВИТЕЛЬНЫЕ БЮДЖЕТНЫЕ СТРАТЕГИИ ПО ЗАКОНОДАТЕЛЬСТВУ ФЕДЕРАТИВНОЙ РЕСПУБЛИКИ ГЕРМАНИИ
}

\begin{abstract}
Аннотация. Объектом исследования являются общественные отношения, складывающиеся в сферах регулирования финансового и муниципального права по поводу того, является ли банкротство муниципального образования необходимым инструментом для ФРГ или в современных стратегиях земель по предотвращению муниципального долга имеются иные пути, позволяющие сделать банкротство ненужным. В предмет исследования вошли теории и концепции немецкого финансового права по проблемам банкротства муниципальных образований; нормы немецкого финансового и муниципального права; российская и немецкая судебная практика по спорам, связанным с вопросами платежеспособности муниципальных образований ФРГ. В основе изучения лежит сравнительно-правовой метод, позволяющий сопоставить сходные правовые проблемы, существующие в немецком и российском законодательстве, а также выявить оптимальные пути их разрешения. Сучетом историко-правового подхода в статье освещен институт бюджетно-правовой ответственности в его генезисе. Научная новизна состоит в том, что на основе новейшего законодательства Федеративной Республики Германии проведено комплексное исследование института банкротства муниципальных образований. При содержательном приближении к составу правонарушения бюджетный кризис рассматривается в привязке к финансовому выравниванию. Это устанавливается в уставах муниципальных образований всех земель как императивное правило. Поскольку межбюджетное выравнивание не может рассматриваться только на кратко- или долгосрочный период, можно констатировать разные этапы критического бюджетного положения. Вопрос заключается в том, насколько своевременно земли способны реагировать на бюджетные правонарушения. Также важным является вопрос о том, какие соответствующие меры по исправлению положения смогут предпринять земли для восстановления платежеспособности общин и их способности к самоуправлению (превентивные меры и их последствия; восстановление стратегий и их ограничений). Первоначальные меры должны быть приняты уже при первом случае несбалансированности бюджета. Таким образом, введение процедуры банкротства для муниципальных образований является дискуссионным вопросом. Связанное с возможностью банкротства или ожидаемое от него стимулирующее действие, вероятно, будет малодейственно, так как возможности для действий на местном уровне сильно ограничены. Кроме того, рассматриваются многочисленные конфликты из-за гарантий самоуправления и межотраслевых связей между землями и общинами. Широко распространенный отказ от коммунального банкротства не может быть расценен как индикатор ненужности этого подхода. Для введения этого института нужны еще и политические инициативы, а из-за противоречий в юридической практике его будет сложно вводить в действие и реализовывать. Возрождение этого инструмента будет, вероятно, ограничено в Германии только в научной дискуссии.
\end{abstract}

Ключевые слова: бюджет, банкротство, муниципальное образование, федерация, федеральные земли, Федеративная Республика Германия, несостоятельность, финансовый кризис, федеративная реформа, платежеспособность.

$\Pi$ ри слове "банкротство», прежде всего, приходит в голову мысль о несостоятельности компании (юридического лица). В действительности неплатежеспособным должником может стать также физическое лицо, муниципальное образование

или суверенное государство. Правовые механизмы банкротства физических лиц и единиц административно-территориального деления страны работают во многих государствах, там же, где они отсутствуют, ведутся дискуссии о возможности введения подобных 
процедур. Образцом для проведения настоящего исследования послужила Федеративная Республика Германии. Особенно пристально будет рассматриваться вопрос о том, как обстоит дело с существующими стратегиями земель по предотвращению бедственного положения местных бюджетов и устранению его последствий. Круг вопросов, подлежащих рассмотрению, очень широк. В частности, влияние введения банкротства общин скорее скажется на политической сфере, нежели на финансово-экономической. Кроме того, возникает вопрос, в какой степени местные органы власти вообще могут предотвратить угрозу неплатежеспособности и насколько активно поддерживают земли свои общины.

В поисках решения бюджетных проблем многими общинами предлагаются разные варианты, в том числе спорные. Особенно далеко пошло предложение о введении процедуры банкротства муниципального образования. Это предложение следует рассматривать как выражение сомнения по поводу эффективности существующих механизмов и инструментов для предотвращения образования долга и управления им. Тем не менее, вопрос целесообразности банкротства муниципального образования является спорным, поскольку неясны его возможные благотворные и негативные последствия. Является ли банкротство муниципального образования необходимым инструментом или в современных стратегиях земель по предотвращению муниципального долга имеются иные пути, позволяющие сделать банкротство ненужным? Этому вопросу посвящено настоящее исследование.

«Производство по делу о несостоятельности в отношении имущества общины является недопустимым». Так, например, говорится в Положении об общинах земли Гессен ${ }^{1}$. Аналогичные положения содержат и законодательные акты других немецких земель. Тем не менее, развитие национального законодательства, а также международных актов порождает в последние годы дискуссии, особенно научные, о необходимости введения процедуры банкротства для муниципальных образований.

Во многом этому способствовал мировой финансовый кризис, который «в течение нескольких месяцев превратился в наибольшую угрозу для мировой экономики со времен Великой депрессии 30-х годов прошлого века» ${ }^{2}$. Последствия этого кризиса обостряют финансовые проблемы на муниципальном уровне. На национальном уровне наблюдается резкий рост муни-

$1 \$ 146$ HessGemO: Hessische Gemeindeordnung in der Fassung der Bekanntmachung vom 7. März 2005 (GVBl. I S. 142), zuletzt geändert durch Gesetz vom 15.11.2007 (GVBl. 2007, S. 757).

2 Beate Balzli u.a.: Irgendwann ist Zahltag, Der Spiegel v. 26.1.2009, S. 51 . ципальных бюджетных кредитов ${ }^{3}$. Только за период с 2000 по 2007 год размер муниципальных долгов вырос с 28,7 млрд. евро в четыре раза.

Часть II федеративной реформы и связанный с ней поиск эффективных механизмов ограничения задолженности федерации и земель также подогревали дискуссию о перспективах введения процедуры банкротства для муниципальных образований ${ }^{5}$ В данном обсуждении это банкротство в Германии не в последнюю очередь связано с введением двойной бухгалтерии. Обеспечиваемая таким образом прозрачность в отношении истинного финансового положения общин поднимает вопрос о том, какие меры в будущем будут применяться к общинам с чрезмерным размером задолженности.

На международном уровне в дополнение к дискуссии по закону о банкротстве известны также случаи банкротства муниципальных образований, например, Лейкербад в Швейцарии ${ }^{6}$ или Рокитнице в Чехии

Как уже упоминалось, банкротство муниципальных образований в Германии запрещено во всех землях. Это не всегда было так. Повторное введение коммунального банкротства потребует соответствующих изменений в законодательстве земель. Однако Федеральный конституционный суд до сих пор не выразил своего мнения относительно конституционности подобных изменений. Но даже если поправки в закон будут теоретически возможны, правовой анализ фактов в немецкой юридической науке считается недостаточным ${ }^{8}$.

Как уже говорилось, банкротство юридических лиц публичного права не предусмотрено законода-

\footnotetext{
3 Deutscher Städtetag, Gemeindefinanzbericht 2008, Der Städtetag 2008 (Heft 5), 6.

4 Statistisches Bundesamt, Finanzen und Steuern, Schulden der öffentlichen Haushalte 2008.

5 Gutachten des Wissenschaftlichen Beirats beim Bundesministerium der Finanzen (April 2005), Haushaltskrisen im Bundesstaat // www.bundesfinanzministerium.de/nn_25412/DE/BMF_ Startseite/Service/Downloads/Abt__/Gutachten_Haushaltskrisen_im_Bundesstaat, templateId=raw, property= publicationFile.pdf (19.1.2009); vgl. Öffentliche Anhörung zur Föderalismusreform II am 22.6.2007, Kommissionsprot. 4, // www.bundestag.de/parlament/gremien/foederalismus2/protokolle/prot04.pdf (13.1.2009).

6 Vgl. Peter Übersax: Erfahrungen und Lehren aus dem „Fall Leukerbad“, Denkanstösse für das schweizerische Gemeinderecht, Basel 2005.

7 Vgl. Beate Jochimsen: Staatsschulden ohne Haftung - Eine Option für die deutschen Bundesländer, Wirtschaftsdienst 2007, $518 \mathrm{ff}$.

8 Duve, Thomas: Die Wiederentdeckung der kommunalen Insolvenz im Kontext bestehender Präventions- und Sanierungsstrategien: in: DÖV 2009, S. 584.
} 
тельством ФРГ (ч. 1 ст. 12 Закона о банкротстве) 9 . Все федеральные земли также приняли это положение. Согласно Закону о надлежащем наделении собственным имуществом институтов, групп учреждений и финансовых холдинговых групп (Solvatibilitätsverordnung) коэффициент риска по муниципальным займам считается равным $0 \%{ }^{10}$. Общинам, равно как и государству, посредством этого приписывается неограниченная платежеспособность. Как следствие, банк-кредитор не должен обеспечивать муниципальный кредит своим имуществом. Согласно Закону о банковских кредитах банк не обязан проверять и учитывать экономические отношения и связи заемщика ${ }^{11}$. Для использования внутренних банковских кредитных рейтингов для муниципалитетов в Германии нет никаких законодательных предписаний.

Из этих норм вытекают некоторые непосредственные следствия для кредитной сделки и всех ее сторон. Для банков здесь идет речь об относительно безрисковых кредитных сделках, к которым они не обязаны привязывать собственный капитал. В дальнейшем банки могут использовать муниципальные кредиты из-за их высокой обеспеченности как подтверждение по банковским гарантиям и закладным. В конечном счете, кредиты впоследствии выдаются муниципалитетам на гораздо более выгодных условиях, и общины выигрывают каждый раз, когда им нужно взять кредит.

Из-за презюмируемой неограниченной платежеспособности по муниципальным заимствованиям банками будут по-прежнему выдаваться кредиты общинам, даже если они уже имеют очень высокий уровень задолженности. В то же время и общины не становятся неплатежеспособными. Земли же, в свою очередь, не дают имущественных поручительств по обязательствам муниципальных образований. Обратной стороной медали является кредитный порочный круг, в результате которого долги растут, а кредиты выдаются снова и снова. В то же время из всего этого нельзя сделать вывод о том, что постоянная доступность кредитов снижает давление на необходимость экономии как землями, так и муниципалитетами.

С введением процедуры банкротства для муниципальных образований ограничение заимствований на местном уровне должно быть нацелено не столько на изменение содержания правовых норм, сколько на

\footnotetext{
9 Insolvenzordnung vom 5. Oktober 1994 (BGBl. I S. 2866)

10 Solvatibilitätsverordnung (Verordnung über die angemessene Eigenmittelausstattung von Instituten, Institutsgruppen und Finanzholding-Gruppen) vom 14. Dezember 2006 (BGBl. I S. 2926)

11 Vgl. Jochen Walter: Banken-Rating für Kommunen, Gemhlt 2004, GEMHLT Jahr 2004 S. 1.
}

стимулирование рыночных механизмов ${ }^{12}$. Кроме того, муниципальные образования, имеющие такой высокий уровень задолженности, что уже не могут самостоятельно погасить ее, посредством введения процедуры банкротства, получали бы возможность для нового старта (эффект реабилитации) ${ }^{13}$.

Когда речь идет о муниципальном банкротстве, не имеется в виду традиционная процедура полной ликвидации активов. Напротив, сторонники коммунального банкротства выступают за процедуру, которая введена в действие Законом о банкротстве с 1 января 1999 года. Особенностью этой процедуры является то, что все участники получат далеко идущую свободу в проведении несостоятельности и "смогут добиться наилучшего решения по возможности беспрепятственно при использовании законодательных установок» ${ }^{14}$.

Как следствие возможного введения банкротства муниципальных образований, банки столкнутся с известным риском прекращения платежей по кредитам. Существующий “нулевой подход" к кредитному риску должен быть пересмотрен. Вероятность прекращения платежей будет определяться на основе кредитных рейтингов. В зависимости от кредитоспособности муниципального образования будут повышаться издержки по заимствованиям, и кредитные условия для общины будут ухудшаться. Согласно подсчетам сторонников банкротства политики будут в будущем в будущем стремиться уменьшить долг, чтобы избежать банкротства. По мнению профессора Ч. Бланкарта, «дело о банкротстве должно быть не только реальным, но устрашающим, а кредиторы и должники должны делать все, чтобы избежать банкротства» ${ }^{15}$.

Если же муниципальное образование находится уже в безвыходном долговом положении, ему должна быть предоставлена возможность для нового старта в рамках модифицированной процедуры банкротства, которая будет функционировать как реорганизационный инструмент. Таким образом, для общины это будет не только путь к освобождению от долгов, но и возможность быстрого восстановления, что будет рас-

12 Charles B. Blankart /Erik R. Fasten/Achim Klaiber: Föderalismus ohne Insolvenz, Wirtschaftsdienst 2006, 571.

13 Christoph G. Paulus: Überlegungen zur Insolvenzfähigkeit von Gemeinden, Zeitschrift für das gesamte Insolvenzrecht (ZInsO) 2003, 869.

14 Eberhard Braun/Achim Frank, in: Eberhard Braun (Hrsg.), Kommentar zur Insolvenzordnung, München 2007, S. 1183.

15 Vgl. Aussage von Prof. Dr. Charles Blankart als Sachverständiger in der öffentlichen Anhörung zur Föderalismusreform II am 22.6.2007, Kommissionsprot. 4, abrufbar unter www.bundestag. $\mathrm{de} /$ parlament/gremien/foederalismus2/protokolle/prot04.pdf (13.1.2009). 


\section{Журнал зарубежного законодательства и сравнительного правоведения $\mathbf{1 \cdot 2 0 1 5}$}

сматриваться как преимущество для того, чтобы в будущем избежать дальнейших обременений ${ }^{16}$.

Однако существуют определенные препятствия введению банкротства в отношении муниципальных образований и связанные с этим проблемы. Так, чтобы получить от введения банкротства ожидаемый эффект стимулирования посредством варьирующихся условий кредитования, земли должны принципиально исключить спасение общин от бедственного финансового положения (например, выкуп проблемных кредитов).

Дальнейшая работа по стимулированию возможна, только если предусмотрено соответствующее пространство для действий. Это пространство из-за низкой доходной автономии и практически нулевой расходной автономии признается недостаточным. Те же муниципальные образования, которые уже были дисциплинированы банкротством, должны будут получить возможность влиять на свое финансовое положение. Эту свободу общины получат лишь ограниченно, поскольку многие задачи были им делегированы, и как следствие, их выполнение установлено законом (например, функции в социальной сфере).

В отличие от частных компаний и хозяйственных обществ, которые, например, могут сократить объем выпускаемой продукции, ввести сокращенный рабочий день или даже изменить место расположения предприятия, для муниципальных образований применение таких мер не представляется возможным.

Кроме того, по доходной части рост вряд ли будет высок. В частности, финансово слабые общины сильно зависят от финансовой помощи земель. В новых федеральных землях доля субсидий из бюджетов земель составляет около $50 \%{ }^{17}$. Именно такие финансово слабые общины и будут наиболее затронуты введением банкротства.

Местные власти мало на что могут повлиять. Муниципальное законодательство, в том числе в сфере финансов, находится в компетенции земель а, следовательно, за пределами сферы непосредственного влияния общин ${ }^{18}$.

Также встает вопрос об определении конкурсной массы. Какое имущество будет туда включаться - только связанное с исполнением собственных полномочий или и с исполнением делегированных полномочий тоже? Зачастую эти собственные и делегированные

16 Vgl. Borchert (Fn. 27), Die Gemeinde SH 2004, 3; vgl. Stefan Frielinghaus, Das Tabu der kommunalen Insolvenz, DÖV 2008, DÖV Jahr 2008 Seite 997.

17 Vgl. Thomas Lenk/Hans-Joachim Rudolph: Die kommunalen Finanzausgleichssysteme in der Bundesrepublik Deutschland, in: Michael Nierhaus (Hrsg.), Kommunalfinanzen - Beiträge zur aktuellen Debatte, Kommunalwissenschaftliches Institut der Universität Potsdam, KWI-Arbeitsheft Nr. 9, Potsdam 2005, S. 57.

18 Vgl. Alma Werner-Jensen: Planungshoheit und kommunale Selbstverwaltung, Baden-Baden 2006, S. 32. задачи сложно четко разграничить. Если взыскания в процессе банкротства будут ограничены сферой добровольно принятых на себя общинами задач, это может привести к предельному сужению сферы собственных полномочий муниципальных образований. Это было бы практически «ликвидацией местного самоуправления» ${ }^{19}$.

Все эти проблемы могут свидетельствовать о том, что муниципальное банкротство на сегодняшний день вряд ли оправдано. Едва ли имеет смысл ввести механизм, который создаст больше проблем, чем решений. Возможны и иные способы привлечения земель к финансовой помощи общинам.

При содержательном приближении к составу правонарушения бюджетный кризис рассматривается в привязке к финансовому выравниванию. Это устанавливается в уставах муниципальных образований всех земель как императивное правило. Поскольку межбюджетное выравнивание не может рассматриваться только на кратко- или долгосрочный период, можно констатировать разные этапы критического бюджетного положения. Вопрос заключается в том, насколько своевременно земли способны реагировать на бюджетные правонарушения. Также важным является вопрос о том, какие соответствующие меры по исправлению положения смогут предпринять земли для восстановления платежеспособности общин и их способности к самоуправлению.

\section{1. Превентивные меры и их последствия.}

К классическим превентивным мерам относят оговорки о разрешении, требования к отчетности местных органов власти, консультации. Поскольку руководство и консультации не являются формальными средствами контроля, существует риск неэффективности, если общины проигнорируют советы надзирающей инстанции ${ }^{20}$.

Некоторые земли начали с создания систем раннего предупреждения. Ведущие позиции занимают здесь Саксония, где уже с 2003 года создается система, основанная на информации Министерства внутренних дел о состоянии местных бюджетов, в том числе местных муниципальных ассоциаций и жилищных компаний. В Мекленбург-Передней Померании, Саксонии-Ангальт и Северной Рейн-Вестфалия такие системы находятся в разработке ${ }^{21}$.

19 Vgl. Faber (Fn. 2), DVBl 2005, DVBL Jahr 2005 Seite 945.

20 Vgl.UweLübking/Klaus Vogelgesang:DieKommunalaufsichtAufgaben, Rechtsgrundlagen, Organisation, Berlin 1998, S. 88.

21 Vgl. Michael Junker: Kennzahlengestützte Bestimmung der dauernden Leistungsfähigkeit von Kommunen in MecklenburgVorpommern - „RUBIKON“ als Beitrag zur Haushaltskonsolidierung, Landes- und Kommunalverwaltung 2007, S. $396 \mathrm{ff}$. 
С момента введения системы раннего предупреждения бюджетные позиции многих муниципальных образований значительно улучшились. Ключевой вопрос состоит в том, какие конкретные действия должны предприниматься в той или иной общине, поскольку одно лишь создание системы раннего предупреждения не меняет финансового положения муниципального образования. Улучшения в бюджетной сфере были достигнуты главным образом за счет расширения контактов уровнями финансового контроля.

\section{2. Восстановление стратегий и их ограничений.}

Не всегда удается избежать несбалансированности бюджета. Как уже отмечалось, община может быть повергнута постоянно несбалансированными бюджетами в бюджетный кризис. Первоначальные меры должны быть приняты уже при первом случае несбалансированности бюджета. Процедура в разных землях примерно одинакова. Но даже здесь заметны некоторые различия. При несбалансированном бюджете в большинстве земель создается концепция бюджетного страхования. Посредством данной меры можно будет «изыскать источники финансирования бюджета на текущий период и избежать дефицита в следующем»²2. В девяти землях создание такой концепции является обязательным ${ }^{23}$. В четырех из них она скоро будет принята. Часто в концепции включаются нормы о поручительстве земель по обязательствам муниципальных образований при выполнении своих полномочий. Поручительство осуществляется при учете требований по соблюдению мер по консолидации бюджетов. Однако зачастую общины попадают в зависимость от подоб- ной помощи, и через некоторое время становятся неспособными отвечать по своим долгам.

Таким образом, введение процедуры банкротства для муниципальных образований является дискуссионным вопросом. Связанное с возможностью банкротства или ожидаемое от него стимулирующее действие, которые должны привести к избеганию катастрофы, вероятно, будет малодейственно, так как возможности для действий на местном уровне сильно ограничены. Кроме того, рассматриваются многочисленные конфликты из-за гарантий самоуправления и межотраслевых связей между землями и общинами. Широко распространенный отказ от коммунального банкротства не может быть расценен как индикатор ненужности этого подхода. Для введения этого института нужны еще и политические инициативы, а из-за противоречий в юридической практике его будет сложно вводить в действие и реализовывать. Возрождение этого инструмента будет, вероятно, ограничено в Германии только в научной дискуссии.

Из эмпирических результатов исследований можно выделить факторы успеха, без которых системы раннего предупреждения будут иметь лишь ограниченное действие: актуальность данных, открытость государственной системы, связи между всеми уровнями, оказание финансовой помощи, эффективный финансовый контроль. Большая часть земель только начинают применять систему раннего предупреждения. Панацеи в бюджетном праве не существует. Причины тому выражаются по-разному. Системы раннего предупреждения могут представлять собой лишь обобщения и не заменяют рассмотрения каждого конкретного случая.

\section{Библиографический список:}

1. Арзуманова Л.Л. Финансовая политика государства: понятие и ее составные элементы // Финансовое право и управление. - 2013. - № 1. - C. 72-78. DOI: 10.7256/.2013.1.9525.

2. Астанин Г.В.. Административная ответственность арбитражных управляющих по законодательству РФ и Украины: сравнительный анализ // Административное и муниципальное право. - 2013. - № 7. - C. 104-107. DOI: 10.7256/19992807.2013.7.9038

3. Болтинова О.В. К вопросу о государственном финансовом контроле в Российской Федерации // Финансовое право и управление. - 2013. - № 2. - C. 39-45. DOI: 10.7256/2310-0508.2013.2.9725.

4. Болтинова О.В. К вопросу о совершенствовании бюджетного законодательства Российской Федерации // Финансовое право и управление. - 2013. - № 1. - С. 56-63. DOI: 10.7256/.2013.1.9547.

5. Бурцева Е.В. Основные подходы к совершенствованию методов оценки финансовой устойчивости промышленных предприятий в условиях нестабильности // Тренды и управление. - 2013. - № 1. - C. 78-89. DOI: 10.7256/23079118.2013.01.9.

6. Воронцова А.И. Ведение бухгалтерского учета и налогообложение в условиях несостоятельности // Налоги и налогообложение. - 2011. - № 12. - С. 104-107.

$22 \S 74$ Abs. 4 Satz 2 GemO Bbg.

23 Vgl. $\$ 74$ Abs. 4 Satz 1 GemO Bbg, $\$ 92$ Abs. 4 Satz 2 HessGemO, $\$ 43$ Abs. 3 Satz 1 GemO MV, $\$ 82$ Abs. 6 Satz 1 NdsGemO, $₫ 76$ Abs. 1 Satz 1 GemO NRW, $\$ 82$ Abs. 4 Satz 1 SaarlGemO, $₫$ SAGO $₫ 72$ Abs. SAGO $₫ 72$ Absatz 4 Satz 1 SächsGemO, $₫ 53$ Abs. 4 Satz 1 ThürGemO. 


\section{Журнал зарубежного законодательства и сравнительного правоведения $\mathbf{1 \cdot 2 0 1 5}$}

7. Гой В.В. Формирование специализированной институциональной системы управления сферой несостоятельности субъектов хозяйствования Украины // Национальная безопасность / nota bene. - 2013. - № 6. - C. 104-107. DOI: 10.7256/2073-8560.2013.6.9998

8. Дорохина Е.Г.. Эффективность государственного управления в сфере банкротства // Административное и муниципальное право. - 2012. - № 8. - С. 104-107.

9. Есаков Г.А., Уве Х., Головненков П.В. Определение субъекта преступлений в сфере экономики в российском и немецком уголовном праве // Журнал зарубежного законодательства и сравнительного правоведения. 2010. № 4. С. $122-132$.

10. Иванова М.М. Необходимость финансовой диагностики состояния предприятия с целью выявления признаков его несостоятельности // Тренды и управление. - 2013. - № 1. - C. 104-107. DOI: 10.7256/2307-9118.2013.01.3

11. Ивлиева М.Ф. О «возмещении» бюджетных расходов // Финансовое право и управление. - 2013. - № 2. - С. 142149. DOI: 10.7256/2310-0508.2013.2.9866.

12. Исправникова Н.Р., Мжачих И.Е. Институт банкротства как часть системы определения и защиты прав собственности в рамках рыночной экономики // Политика и Общество. - 2012. - № 10. - С. 104-107.

13. Колесников Ю.А. Финансово-правовое обеспечение передачи части государственных полномочий органам местного самоуправления // Административное и муниципальное право. - 2012. - 5. - С. 18 - 21.

14. Лагутин И.Б. Организационная основа российского бюджетного контроля: административно-правовое обеспечение // Административное и муниципальное право. - 2012. - 9. - С. 49 - 53.

15. Морозова О.С., Грачева Е.Ю. Финансово-правовое регулирование межбюджетных отношений в ФРГ // Финансовое право и управление. - 2013. - № 1. - C. 51-55. DOI: 10.7256/.2013.1.9538.

16. Разгильдиева М.Б. Теоретические проблемы бюджетно-правовой ответственности // Финансовое право и управление. - 2013. - 2. - C. 102 - 118. DOI: 10.7256/2310-0508.2013.2.9876.

17. Савин А.А. Организация и ведение учета налогообложения при несостоятельности предприятий (организаций) // Налоги и налогообложение. - 2012. - № 7. - С. 104-107.

18. Соколова Э.Д. Правовое регулирование бюджетной деятельности государства и муниципальных образований (теория и правотворчество) // Финансовое право и управление. - 2013. - № 2. - С. 119-135. DOI: 10.7256/23100508.2013.2.9868.

19. Соловова Е.В. Выпуск государственных и муниципальных ценных бумаг как способ привлечения заемных средств в США // Финансовое право и управление. - 2013. - № 1. - С. 16-23. DOI: 10.7256/.2013.1.9498.

20. Тихонов Д.В. Пути решения проблемы укрепления собственной доходной базы муниципальных образований (на примере Нижегородской области) // Административное и муниципальное право. - 2012. - 9. - С. 62 - 66.

21. Трофимова И.Н. Местное самоуправление в современных концепциях публичного управления // Тренды и управление. - 2013. - № 2. - С. 187-195. DOI: 10.7256/2307-9118.2013.2.5022.

22. Химичева Н.И. Принципы современного российского финансового права как основы бюджетно-правового регулирования // Финансовое право и управление. - 2013. - № 2. - C. 68-76. DOI: 10.7256/2310-0508.2013.2.9860.

23. Balzli, Beate u.a.: Irgendwann ist Zahltag, Der Spiegel v. 26.1.2009, S. 51.

24. Blankart, Charles B. / Fasten, Erik R. / Klaiber, Achim: Föderalismus ohne Insolvenz, Wirtschaftsdienst 2006, 571.

25. Borchert (Fn. 27), Die Gemeinde SH 2004, 3; vgl. Stefan Frielinghaus, Das Tabu der kommunalen Insolvenz, DÖV 2008, DÖV Jahr 2008 Seite 997.

26. Braun, Eberhard / Frank, Achim in: Eberhard Braun (Hrsg.), Kommentar zur Insolvenzordnung, München 2007, S. 1183.

27. Duve, Thomas: Die Wiederentdeckung der kommunalen Insolvenz im Kontext bestehender Präventions-und Sanierungsstrategien: in: DÖV 2009, S. 584.

28. Jochimsen, Beate: Staatsschulden ohne Haftung - Eine Option für die deutschen Bundesländer, Wirtschaftsdienst 2007, 518ff.

29. Junker, Michael: Kennzahlengestützte Bestimmung der dauernden Leistungsfähigkeit von Kommunen in MecklenburgVorpommern - „RUBIKON“ als Beitrag zur Haushaltskonsolidierung, Landes-und Kommunalverwaltung 2007, S. 396ff.

30. Lenk, Thomas/ Rudolph, Hans-Joachim: Die kommunalen Finanzausgleichssysteme in der Bundesrepublik Deutschland, in: Michael Nierhaus (Hrsg.), Kommunalfinanzen - Beiträge zur aktuellen Debatte, Kommunalwissenschaftliches Institut der Universität Potsdam, KWI-Arbeitsheft Nr. 9, Potsdam 2005, S. 57.

31. Lübking, Uwe / Vogelgesang, Klaus: Die Kommunalaufsicht - Aufgaben, Rechtsgrundlagen, Organisation, Berlin 1998, S. 88.

32. Paulus, Christoph G.: Überlegungen zur Insolvenzfähigkeit von Gemeinden, Zeitschrift für das gesamte Insolvenzrecht (ZInsO) 2003, 869.

33. Übersax, Peter: Erfahrungen und Lehren aus dem „Fall Leukerbad“, Denkanstösse für das schweizerische Gemeinderecht, Basel 2005.

34. Walter, Jochen: Banken-Rating für Kommunen, Gemhlt 2004, GEMHLT Jahr 2004 S. 1.

35. Werner-Jensen, Alma: Planungshoheit und kommunale Selbstverwaltung, Baden-Baden 2006, S. 32.

\section{References (transliteration):}

1. Арзуманова Л.Л. Финансовая политика государства: понятие и ее составные элементы // Финансовое право и управление. - 2013. - № 1. - С. 72-78. DOI: 10.7256/.2013.1.9525.

2. Астанин Г.В.. Административная ответственность арбитражных управляющих по законодательству РФ и Украины: сравнительный анализ // Административное и муниципальное право. - 2013. - № 7. - C. 104-107. DOI: 10.7256/19992807.2013.7.9038 
3. Болтинова О.В. К вопросу о государственном финансовом контроле в Российской Федерации // Финансовое право и управление. - 2013. - № 2. - С. 39-45. DOI: 10.7256/2310-0508.2013.2.9725.

4. Болтинова О.В. К вопросу о совершенствовании бюджетного законодательства Российской Федерации // Финансовое право и управление. - 2013. - № 1. - С. 56-63. DOI: 10.7256/.2013.1.9547.

5. Бурцева Е.В. Основные подходы к совершенствованию методов оценки финансовой устойчивости промышленных предприятий в условиях нестабильности // Тренды и управление. - 2013. - № 1. - C. 78-89. DOI: 10.7256/23079118.2013.01.9.

6. Воронцова А.И. Ведение бухгалтерского учета и налогообложение в условиях несостоятельности // Налоги и налогообложение. - 2011. - № 12. - С. 104-107.

7. Гой В.В. Формирование специализированной институциональной системы управления сферой несостоятельности субъектов хозяйствования Украины // Национальная безопасность / nota bene. - 2013. - № 6. - C. 104-107. DOI: 10.7256/2073-8560.2013.6.9998

8. Дорохина Е.Г.. Эффективность государственного управления в сфере банкротства // Административное и муниципальное право. - 2012. - № 8. - С. 104-107.

9. Есаков Г.А., Уве Х., Головненков П.В. Определение субъекта преступлений в сфере экономики в российском и немецком уголовном праве // Журнал зарубежного законодательства и сравнительного правоведения. 2010 . № 4. С. $122-132$.

10. Иванова М.М. Необходимость финансовой диагностики состояния предприятия с целью выявления признаков его несостоятельности // Тренды и управление. - 2013. - № 1. - C. 104-107. DOI: 10.7256/2307-9118.2013.01.3

11. Ивлиева М.Ф. О «возмещении» бюджетных расходов // Финансовое право и управление. - 2013. - № 2. - С. 142149. DOI: $10.7256 / 2310-0508.2013 .2 .9866$.

12. Исправникова Н.Р., Мжачих И.Е. Институт банкротства как часть системы определения и защиты прав собственности в рамках рыночной экономики // Политика и Общество. - 2012. - № 10. - С. 104-107.

13. Колесников Ю.А. Финансово-правовое обеспечение передачи части государственных полномочий органам местного самоуправления // Административное и муниципальное право. - 2012. - 5. - С. 18 - 21.

14. Лагутин И.Б. Организационная основа российского бюджетного контроля: административно-правовое обеспечение // Административное и муниципальное право. - 2012. - 9. - С. 49 - 53.

15. Морозова О.С., Грачева Е.Ю. Финансово-правовое регулирование межбюджетных отношений в ФРГ // Финансовое право и управление. - 2013. - № 1. - C. 51-55. DOI: 10.7256/.2013.1.9538.

16. Разгильдиева М.Б. Теоретические проблемы бюджетно-правовой ответственности // Финансовое право и управление. - 2013. - 2. - C. 102 - 118. DOI: 10.7256/2310-0508.2013.2.9876.

17. Савин А.А. Организация и ведение учета налогообложения при несостоятельности предприятий (организаций) // Налоги и налогообложение. - 2012. - № 7. - С. 104-107.

18. Соколова Э.Д. Правовое регулирование бюджетной деятельности государства и муниципальных образований (теория и правотворчество) // Финансовое право и управление. - 2013. - № 2. - С. 119-135. DOI: 10.7256/23100508.2013.2.9868.

19. Соловова Е.В. Выпуск государственных и муниципальных ценных бумаг как способ привлечения заемных средств в США // Финансовое право и управление. - 2013. - № 1. - С. 16-23. DOI: 10.7256/.2013.1.9498.

20. Тихонов Д.В. Пути решения проблемы укрепления собственной доходной базы муниципальных образований (на примере Нижегородской области) // Административное и муниципальное право. - 2012. - 9. - С. 62 - 66.

21. Трофимова И.Н. Местное самоуправление в современных концепциях публичного управления // Тренды и управление. - 2013. - № 2. - С. 187-195. DOI: 10.7256/2307-9118.2013.2.5022.

22. Химичева Н.И. Принципы современного российского финансового права как основы бюджетно-правового регулирования // Финансовое право и управление. - 2013. - № 2. - C. 68-76. DOI: 10.7256/2310-0508.2013.2.9860. 